\title{
Expanded adipose derived mesenchymal stromal cells are effective in treating chronic insertional patellar tendinopathy: clinical and MRI evaluations of a pilot study
}

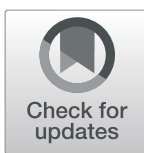

Miguel A. Khoury ${ }^{1}$, Karim Chamari ${ }^{2}$, Montassar Tabben $^{2^{*}}$ (D, Khalid Alkhelaifi ${ }^{2}$, Trueba Ricardo ${ }^{3}$, Couto Damián $^{4}$ and Pieter D'hooghe ${ }^{2}$

\begin{abstract}
Purpose: Effect of ultrasound guided injections of autologous ASCs in chronic recalcitrant patellar tendinopathy. Methods: Fourteen patients (16 knees, 12/2 males/females) with chronic, recalcitrant (unsuccessfully treated with nonoperative treatments) insertional PT underwent clinical evaluation and magnetic resonance imaging (MRI) before intervention. Stromal vascular fraction cells (SVF) were expanded by in-vitro culture and characterized by flow cytometry. Players were injected with three bi-weekly injections of ASCs followed by physiotherapy. They underwent serial clinical evaluations during a 12-month period with repeated MRI at 6-month post-injection.

Results: Victorian Institute of sports assessment-patellar tendon questionnaire (VISA-P) scores improved from $43.8 \pm$ 4.9 at baseline to $58.1 \pm 7.1,70.3 \pm 7.9$ and $78.7 \pm 7.5$ at 3,6 , and 12 months follow-up, respectively. $(p=0.0004$ comparing each variable with the previous one). Mean Visual analogue pain in sports (VAS-sport) score during practice significantly decreased from $7.4 \pm 0.5$ at baseline to $5.2 \pm 1.59(p=0.0005), 3.3 \pm 1.1(p=0.0004)$ and $1.5 \pm$ $0.7(P=0.0004)$ at 3,6 , and 12 months, respectively. Mean Tegner-scores for patients were $8.0 \pm 0.8$ before injury and $2.3 \pm 0.9$ before treatment, thereafter, improving to $4.8 \pm 0.8$ and $7.2 \pm 0.7$ at 6 - and 12 - months, respectively $(p=$ 0.0001). MRI assessed tendon width' did not change over the first 6 months post-intervention. Significant changes were observed for: tendon thickness ( $12.8 \pm 1.1$ to $10.9 \pm 0.7, P=0.0001)$; tear length $(9.3 \pm 1.3$ to $2.3 \pm 0.7, P=$ $0.0001)$, tear width $(6.3 \pm 0.8$ to $3.4 \pm 0.4, P=0.0001)$, and tear thickness ( $4.6 \pm 0.4$ to $2.6 \pm 0 ., P=0.0001)$ at baseline and 6 months, respectively.

Conclusion: Patients with recalcitrant insertional PT showed significant clinical improvement and structural repair at the patellar insertional tendinopathy after injections of autologous ASCs. Results of this study are promising and open a new biological therapeutic modality to treat PT.
\end{abstract}

Keywords: Cell therapy, Tendon healing, jumper's knee, Chronic tendinopathy, Patellar tendon

\footnotetext{
* Correspondence: Montassar.Tabben@aspetar.com

${ }^{2}$ Aspetar Qatar Orthopaedic and Sports Medicine Hospital, P.O. Box 29222,

Doha, Qatar

Full list of author information is available at the end of the article
}

\section{Springer Open}

(c) The Author(s). 2021 Open Access This article is licensed under a Creative Commons Attribution 4.0 International License, which permits use, sharing, adaptation, distribution and reproduction in any medium or format, as long as you give appropriate credit to the original author(s) and the source, provide a link to the Creative Commons licence, and indicate if changes were made. The images or other third party material in this article are included in the article's Creative Commons licence, unless indicated otherwise in a credit line to the material. If material is not included in the article's Creative Commons licence and your intended use is not permitted by statutory regulation or exceeds the permitted use, you will need to obtain permission directly from the copyright holder. To view a copy of this licence, visit http://creativecommons.org/licenses/by/4.0/. 


\section{Introduction}

Insertional patellar tendinopathy (PT), commonly known as jumper's knee, is a highly limiting overuse injury often found in athletes who engage in repetitive forceful loading of the knee extensor apparatus particularly in those with a high volume of training [13].

More specifically, the prevalence of PT has been shown to be highest among sports involving jumping (e.g.volleyball and basketball) and/or involving running and kicking (e.g.soccer and track and field) [25]. Risk factors like gender (males), amount of hours of training, hamstring flexibility and previous knee injury were reported [26]. PT might result in long-lasting symptoms after an athletic career which is an important aspect for the athletes health on the long term [18].

In chronic and recalcitrant cases, surgery might be indicated. In that regard, a randomized study showed that more than half of the patients still had persisting pain at 12 months follow-up post-surgery [3]. The histopathology underlying this condition mainly involves: microinjury of tendon fibers, mucoid degeneration, necrosis, loss of transitional fibrocartilage tissue that attaches to bone generally without inflammation, and increased apoptotic cell death [24].

Healing the tendon and minimizing scar tissue formation, recovering structural properties and reinforcing tensile strength is the goal of biological treatments [26]. By definition, stromal/mesenchymal cells are able to selfrenew and exist in every human tissue in an undifferentiated or unspecialized state. These cells are capable of differentiating or specializing along multiple lineages $[2,4]$, and adipose tissue is an excellent source of adipose derived mesenchymal stromal cells (ASCs). These have been receiving increasing attention over the years toward enhancing tendon healing. Evidences from in vitro and in vivo studies suggest that ASCs can contribute to accelerate and improve the quality of healed tendons [28].

We hypothesized that ultrasound guided injections of autologous ASCs in chronic recalcitrant patellar tendinopathy may be useful in healing the damaged tendon and further decreasing the need of surgery and a successful return to play. We also aimed at assessing the role of MRI evaluation in this pathology and intrinsically evaluate the safety of ASCs culture preparation as an alternative treatment of PT.

\section{Material and methods}

This prospective longitudinal case series exploratory study was approved by the ethical committee of Regen$\operatorname{erar}^{R}$ laboratory (Clinical Trial MR00124). Patients with patellar tendinopathy who referred to our institution from January 2015 to February 2019 were invited to participate giving signed informed consent. Before intervention, a detailed clinical history was performed and visual analog scale (VAS) for maximun pain in sports participation [12], Knee Victorian Institute of sports assessment-patellar tendon questionnaire (Visa-P) [38], Tegner-score before symptoms onset and pre-treatment [6] X-rays and MRI evaluations of the concerned knee were performed. The diagnosis of patellar tendinopathy was confirmed using MRI standard imaging protocol. The intervention consisted in three bi-weekly doses of $8 \times 0^{6}$ ASCs. The follow-up protocol (Table 1) included VAS-sport [12]. Visa-P questionnaire, patient satisfaction and adverse events at 3, 6 and 12 months. MRI was repeated at 6 months and Tegner-score at 6 and 12 months. Minimum clinically important difference (MCID) were considered present when a difference of 13 points in Visa-P [38], 2 points in VAS-sport [12] and 1 point in Tegner [38] were identified. Patient satisfaction was evaluated using a scale including the following categories: improved symptoms, no change-, and worsesymptoms during the practice of sports.

\section{Deleted \\ Participants}

A total of 16 patients (males $=14$; females $=2$ ) were initially recruited (Table 1 ). They all presented the following standard physician established diagnostic criteria: (i) history of exercise-related pain located at the PT insertion for at least 6 months, (ii) tenderness to palpation of the tendon substance and a positive result from an MRI (thickening and tear of the patellar tendon). Patients had to have already unsuccessfully attempted to treat their conditions with exercise-based rehabilitation and different treatment modalities for a minimum of 6 months. Patients were excluded if they had a history of knee or patellar tendon surgery or any inflammatory or prominent degenerative joint condition affecting the knee, contraindication to injection therapy, bleeding diathesis or being on anti-coagulants, local or systemic infection, injections of corticosteroid medication in the past 3 months. All participants were classified as having a degree 3B Blazina classification [5]. Two male patients (number 15 and 16 in Table 1) withdrew consent 3 and 6 months after injections and had surgical treatment. These two patients had a baseline scores of 44 and 45 in VISA-P, 7.5 and 7.2 in VAS-Sp, 2 and 1 in Tegner scores with no improvements at 3 months. All remaining 14 patients were followed during the 12 months' period.

No patients have previously received mesenchymal cells due to any medical condition.

\section{Intervention}

Collection, Characterization and Isolation of Adipose Tissue

This intervention has been performed according to validated procedures already published [19]. Briefly ASCs were stained with antibodies against CD73, CD90, 
Table 1 Sample description

\begin{tabular}{|c|c|c|c|c|c|c|c|c|c|}
\hline Patient & Side & Sex & Age & BMI & Symp. Month & Hour/ Week & Sport & Previous Treatment & MRI \\
\hline 1 & & $\mathrm{~F}$ & 24 & 21.2 & 12 & 10 & Running & Polidocanol & BME-IFPE \\
\hline 2 & & $\mathrm{~F}$ & 38 & 22.3 & 24 & 12 & Running & Corticosteroids -ESWT & BME-IFPE \\
\hline 3 & & M & 18 & 23.4 & 18 & 11 & Running & PRP & BME \\
\hline 4 & & M & 35 & 25.1 & 18 & 11 & Running & PRP-ESWT & - \\
\hline 5 & & M & 28 & 24.4 & 11 & 12 & Soccer & Prolotherapy & - \\
\hline 6 & & M & 41 & 25.3 & 30 & 12 & Soccer & PRP & BME-IFPE \\
\hline 7 & & M & 43 & 24.7 & 21 & 12 & Soccer & Corticosteroids -Polidocanol & - \\
\hline 8 & & M & 31 & 24.3 & 24 & 9 & Volley & PRP & IFPE \\
\hline 9 & & M & 46 & 23.7 & 24 & 9 & Volley & ESWT & IFPE \\
\hline 10 & & M & 48 & 23.8 & 19 & 11 & Handball & ESWT & BME \\
\hline 11 & & M & 37 & 23 & 16 & 9 & Athletic & PRP-ESWT & - \\
\hline 12 & & M & 45 & 24.1 & 13 & 8 & Basketball & Prolotherapy- PRP & - \\
\hline 13 & Bilateral & M & 23 & 23.1 & 25 & 11 & Basketball & Prolotherapy & - \\
\hline 14 & Bilateral & M & 27 & 24.1 & 13 & 8 & Running & PRP & Bilateral BME \\
\hline 15 & & M & 43 & 25.3 & 36 & 7 & Tennis & PRP & - \\
\hline 16 & & M & 45 & 26.7 & 24 & 5 & Soccer & ESWT & IFPE \\
\hline
\end{tabular}

BME Bone Marrow Edema, IFPE Infrapatellar Fat Pad Edema, PRP Platelet Rich Plasma, ESWT Extracorporeal Shock Wave Therapy

CD105, CD45, CD34, CD11b, CD19 or CD79a, CD14, and HLA class II, to determine surfer marker expression. In accordance with the International Society for Cellular Therapy (ISCT) recommendations: $\geq 95 \%$ of the MSC population expressed CD105, CD73 and CD90, as measured by flow cytometry. Additionally, these cells lacked expression $(\leq 2 \%$ positive) of CD $45, \mathrm{CD} 34, \mathrm{CD} 14$ orCD11b, CD79a or CD19 and HLA-DR (class II.20) Also, the cells were able to differentiate to osteoblasts, adipocytes and chondroblasts under standard in vitro differentiating conditions [14]. FACS Canto II BD flow cytometer instrument was used for running samples. The samples were immunostained with a determined panel of monoclonal antibodies (mentioned above) conjugated with different fluorochromes and mouse isotype antibodies were used as control. The results were analyzed with the software Infinicyt version 1.7i.

\section{Percutaneous ultrasound guided intra-lesional delivery of ASCs}

Autologous ASCs were injected at an average of 1 month after tissue collection. The cultured ASCs were washed twice and suspended in $3 \mathrm{ml}$ of HBSS (Gibco, Cat \# 14025088). Prior to the injection, the skin was prepared by aseptic technique with iodine solution. An average of $6 \times 10^{6}$ ASCs were injected 3 times separated by two weeks in each of the affected tendon. The cells were delivered percutaneously under local anesthesia (2\% lidocaine was previously superficially injected to numb the skin). An ultrasound equipment (Esaote X6, L 4-15 $\mathrm{mHz}$ probe) was used to guide injections which were performed by the same physician (MAK). the injection was performed deep into the tendon substance reaching $\mathrm{t}$ the hypoechoic area (Fig. 1).

\section{Postprocedure protocol}

Immediately after the injection, the patient was kept in a seated position without moving the legs for $15 \mathrm{~min}$. Patients were sent home with instructions to rest for approximately $24 \mathrm{~h}$ before performing any physical activity. If necessary, patients were allowed to use acetaminophen $500 \mathrm{mg}$ every $6 \mathrm{~h}$. Only 5 patients used it during the first $48 \mathrm{~h}$ post-injection. Use of nonsteroidal antiinflammatory medication was not allowed. After $48 \mathrm{~h}$, patients were prescribed an initial standardized rehabilitation protocol to follow for 2 weeks under the supervision of a physiotherapist. A formal eccentric muscleand tendon-strengthening program was initiated after this program. At 2 months after the third injection, patients were clinically evaluated to determine the proceeding with progression of the successive individualized rehabilitation or recreational activities as part of the protocol. Patellar tendinopathy was treated by application of eccentric exercise with the use of a decline board. The decline enables better isolation of the knee extensor mechanism in squat exercises [32].

\section{Magnetic resonance imaging}

The equipment used was a $1.5 \mathrm{~T}$ MRI scanner (Philips, Eindhoven, The Netherlands) Flex-M Coil. An 8-channel coil was used with patients in the supine position and the affected leg extended. STIR Coronal, Axial \& Sagital 


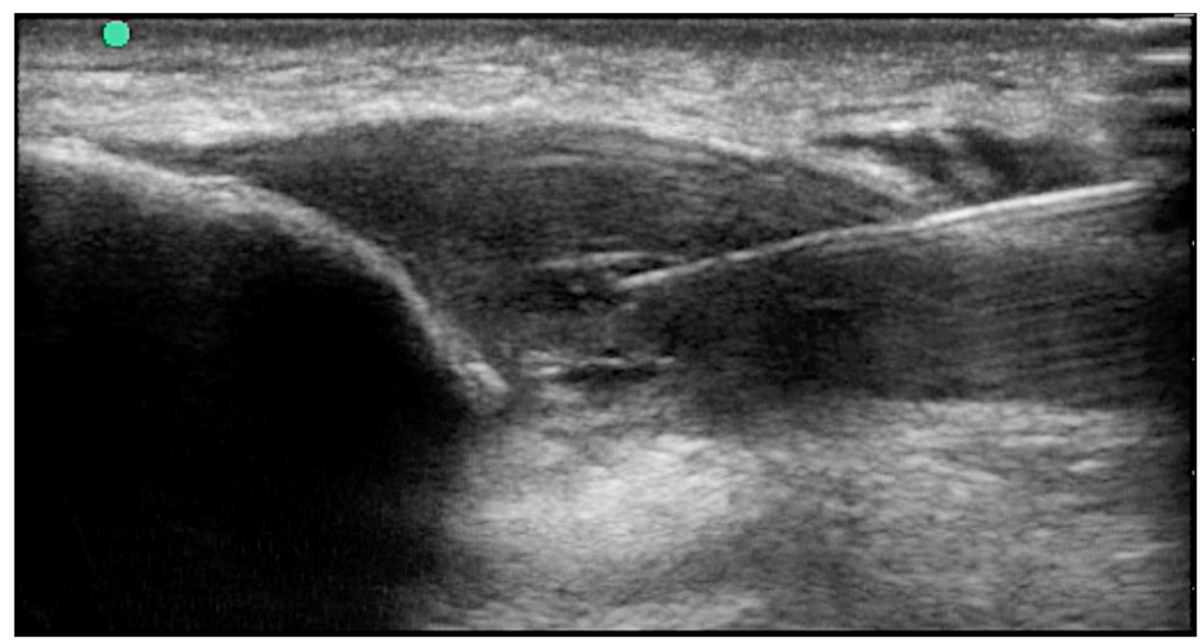

Fig. 1 Ultrasound guided cell injection into the hypoechoic area of the proximal patellar tendon

view (FOV $130 \mathrm{~mm}$, TR 3500, TE 50, TI 100) Cut thickness $3 \mathrm{~mm}$. The evaluation included the extent of tendinosis and tendon tear. The radiological interpretation was performed by two experienced sports trauma radiologists [15].

Images were reviewed on our institutional picture archiving and communication system (PACS). An electronic caliper tool in PACS was used to determine patellar tendon measurements; therefore, all measurements taken were automatically standardized. Tendon dimensions were measured with sagittal or axial (anterior to posterior) views: (A) thickness (anterior to posterior) of the patellar tendon on the first axial slice below the inferior patellar bone. (B), width (medial to lateral) of the patellar tendon, (C) length of the tear, (D) thickness of the tear and (Fig. 2 A); (E) width of the tear (Fig. $1 B)$. The tear length dimension $(C)$, were measured with sagittal MRI scans that showed maximum dimension of the tear. The thickness and width dimensions (D and E) were measured in the axial view that maximally showed each dimension, which corresponded to 1 slice below the inferior pole of the patella.

\section{Statistics}

Data were processed with Stata 14.1 software (StataCorp, Texas, USA). Values are displayed as mean \pm standard deviation (SD) or median and range, according to the variable distribution. Normality of numerical variables was verified using the Wilk-Shapiro test. To compare values at two different times, Paired t-test or Wilcoxon sign rank test were used if variables were normally distributed or not, respectively. $P<0.05$ were considered statistically significant.

\section{Results}

A total of 16 knees (7 left, 9 right) from 14 patients (12 male, 2 female) with a mean age of $34.6 \pm 9.5$ years were prospectively evaluated. Mean BMI was $23.7 \pm 1.1 \mathrm{~kg} / \mathrm{m}^{2}$, median time of Chronic Insertional Patellar Tendinopathy

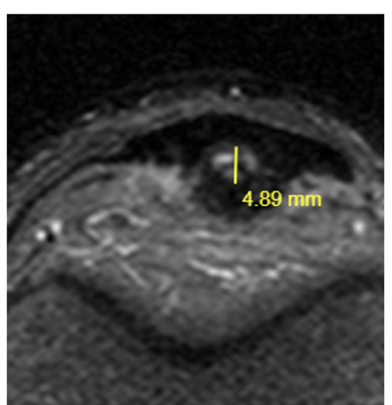

A

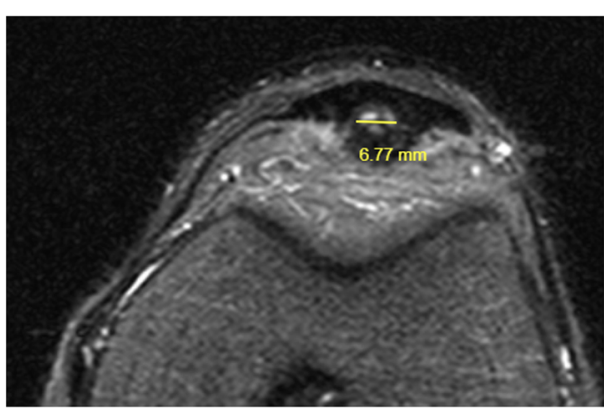

B

Fig. 2 A MRI evaluation: Thickness of the tear. B Width of the tear 
symptoms was 18 (range 11-30) months and median of training time, $11 \mathrm{~h} /$ week (range 8-12).

\section{Clinical results}

Clinical evaluations are presented in Table 2.

VISA-P significantly improved at 3, 6 and 12 months (Table 3) compared to pre-intervention $(p<0.001)$. Figure 3 shows individual Knee Visa-P scores. Baseline, 3, 6 and 12 months.

Visa-P score minimum clinically important difference (MCID) of 13 points compared to the baseline were present in 12 cases at 3 months and in all the 16 cases at 6 months.

Mean Pain during practice (VAS-Sport) score significantly improved at 3,6 , and 12 months (Table 3 ) compared to pre-intervention $(p<0.001)$. Figure 4 shows individual Knee VAS-Sport at Baseline, 3, 6, and 12 months.

VAS-Sp minimum clinically important difference (MCID) of 2 points compared to baseline were present in 7 cases at 3 months, in 15 cases at 6 months and in the all the 16 cases at 12 months.

Mean Tegner-scores for patients were of $8.0 \pm 0.8$ before injury and $2.3 \pm 0.9$ before treatment $(p<0.0001)$. Tegner-score significantly improved at 6 and 12 months compared (Table 3$)$ to pre-intervention $(p<0.001)$. Figure 5 shows individual Tegner-score values before injury, before treatment (Baseline) and at 6 and 12 months post-treatment.

Compared to Tegner-score before treatment, MCID of 1-point improvement was observed in 15 cases at 6 months and in all the 16 cases at 12 months based. In 7 cases, at 12 months, the Tegner scores returned to preinjury values.

\section{MRI score evaluation}

MRI evaluation scores are shown in Table 3.

In pre-treatment MRI, 7 knees had Bone marrow edema (BME) of the inferior pole of the patella, 5 knees had infrapatellar fat pad edema (IFPE) and 3 knees had combined BME and IFPE. Progression of healing of the patellar tendon was observed in all knees. Figs. 6, 7, 8, 9.

\section{Patient satisfaction}

Of the 14 patients (16 knees), at 3 months' postinjection, 9 patients were improved, 4 patients reported

Table 2 Clinical evaluation

\begin{tabular}{lllll}
\hline & Pretreatment & 3 months & $\mathbf{6}$ months & 12 months \\
\hline Knee Visa-P score & $43.8 \pm 4.9$ & $58.1 \pm 7.1^{*}$ & $70.3 \pm 7.9^{*}$ & $78.7 \pm 7.5^{*}$ \\
Pain (VAS-Sport) & $7.4 \pm 0.5$ & $5.2 \pm 1.59^{*}$ & $3.3 \pm 1.1^{*}$ & $1.5 \pm 0.7^{*}$ \\
Tegner-score & $2.3 \pm 0.9$ & - & $4.8 \pm 0.8^{*}$ & $7.2 \pm 0.7^{*}$ \\
\hline
\end{tabular}

*Statistically significant differences comparing each value with the previous one $(p<0.001)$
Table $3 \mathrm{MRI}$ Outcomes (expressed in $\mathrm{mm}$ )

\begin{tabular}{llll}
\hline MRI & Baseline Before treatment & 6 Months & $\boldsymbol{P}$ value \\
\hline Tendon-width & $30.8 \pm 2.6$ & $30.7 \pm 2.5$ & 0.3724 \\
Tendon-thickness & $12.8 \pm 1.1$ & $10.9 \pm 0.7$ & 0.0004 \\
Tear- length & $9.3 \pm 1.3$ & $2.3 \pm 0.7$ & 0.0004 \\
Tear- width & $6.3 \pm 0.8$ & $3.4 \pm 0.4$ & 0.0004 \\
Tear thickness & $4.6 \pm 0.4$ & $2.6 \pm 0.7$ & 0.0004 \\
\hline
\end{tabular}

no change and 1 patient as being worse. At 6 months' evaluation, 1 patient reported disappearance of symptoms, 10 patients improved symptoms and 3 with no change. At 12 months, 9 patients were reported disappearance of symptoms, and 7 with improved symptoms. Thirteen of the patients were ready to undergo the procedure again if needed and 13 of 14 patients would recommend this procedure to other athletes.

\section{Adverse events}

One subcutaneous haematoma and further induration were observed in the site of tissue harvest. It resolved without further treatment. No other complications were observed. No residual symptoms or disability in the periumbilical zone was observed. There were no infections, or other untoward effects.

\section{Discussion}

This study showed that 3 injections of ultrasound guided ASCs were effective in decreasing pain and improving functional and structural repair during the 12 months follow-up of patients with chronic recalcitrant insertional PT. In addition, this study showed that these injections were safe. The structural repair of the tendons was evidenced by MRI at 6 -months.

Current PT treatments include exercises, load management and biomechanical interventions [1]. Placebocontrolled studies including shockwave therapy [22], corticosteroid [21], sclerosing injections with polidocanol [17], and Leucocyte rich or Leucocyte poor platelet plasma [35] have been reported with different degrees of effectiveness yet leaving a substantial number of patients with persisting symptoms $[17,21,22]$.

The present study supports the promising results using cell therapy in previous manuscripts. Pascual Garrido et.al. showed statistically clinical improvement at 5year follow-up with non-expanded BM-MNCs (Bone Marrow Mononuclear cells) inoculation for the treatment of chronic patellar tendinopathy [30]. Although the optimal cell number to treat this condition is not known, a potential advantage of our procedure was that we were able to implant a higher number of mesenchymal stromal cells compared to the number of stromal cells provided by BMAC procedures, that yields less than $1 \%$ of mesenchymal stromal cells per procedure [36]. 


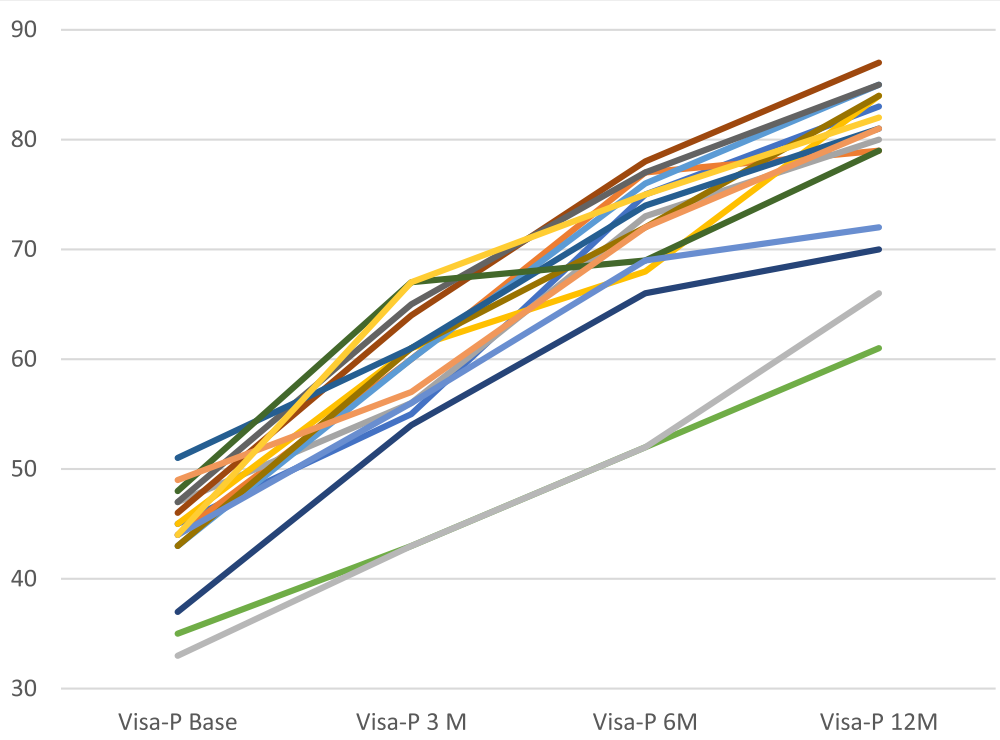

Fig. 3 Individual Knee Victorian Institute of sports assessment-patellar tendon questionnaire (Visa-P) scores. Baseline, 3, 6 and 12 months

Clarke et al. [9] using ultrasound-guided injection of expanded autologous skin-derived tendon-like cells concluded that they can be safely used to treat patellar tendinopathy with, in the short term, faster response of treatment and significantly greater improvement in pain and function than injection of plasma alone. The use of ASCs to treat lateral elbow tendinopathy with promising results has also been reported by our group [19].

It has been previously shown that the responsiveness of the VISA-P scale for patellar tendinopathy in athletes who showed an absolute change greater than 13 points in the VISA-P score (or 15.4-27\% of relative change) achieved a 98\% probability of a minimal important change (MICD) in their status. In contrast there was only a $45 \%$ probability of change when minimum clinically important difference (MICD) was not achieved [16]. In our study, we used the MCID of the VISA-P, to determine whether such a difference is present over time and MICD was obtained during the 12 months followup evaluation. The improvement for successful treatments in the VISA-P score from baseline to the 12 months follow-up was 34,9 points. MCID of 13 points compared to pre-intervention were present in 12 knees at 3 months and in all the 16 knees at 6 months. In our

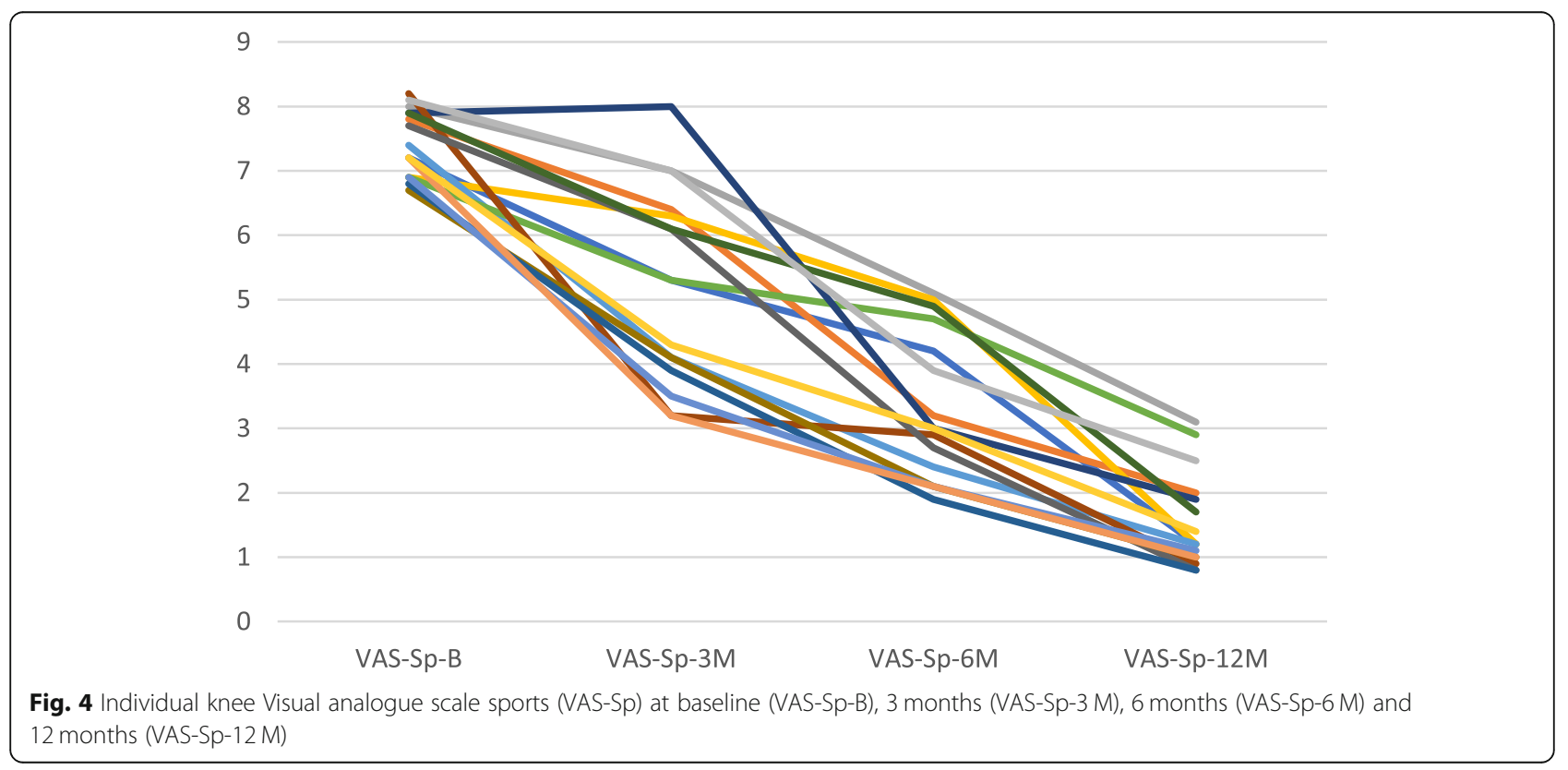




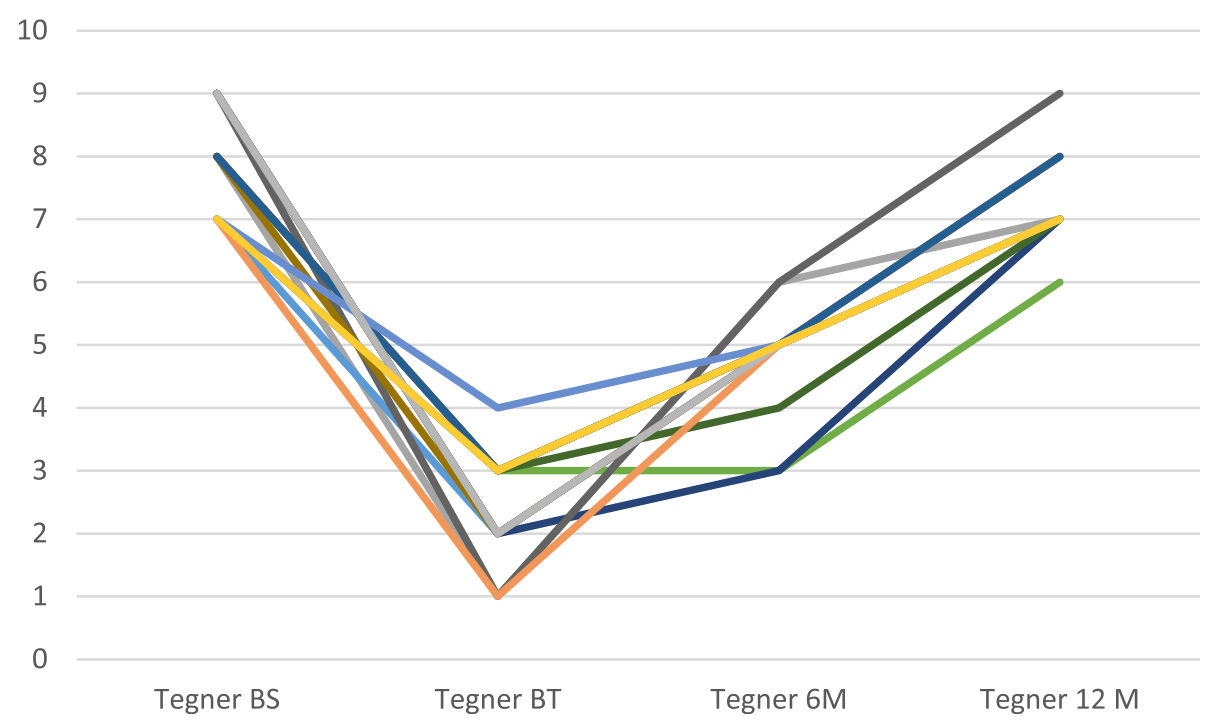

Fig. 5 Individual patient Tegner Score: BS: Before symptoms, BT: Before treatment, $6 \mathrm{M}: 6$ months post-treatment and $12 \mathrm{M}$ : 12 months post-treatment

study 14 out of the 16 knees had 64 points or greater at 6 months post-injection with the observed clinical improvement. It has been also shown that symptomatic, players with insertional patellar tendinopathy are still able to play with Visa-p score of around 64 points [25]. Taking all this information together we can assume that our results are effective in allowing players to return to play.

Surgical treatment has been recommended when nonoperative treatment fails. In a review, Coleman et al. [10] reported in a literature review, that the success rates ranged from $54 \%$ to $100 \%$ after open patellar tenotomy, with an "overall" success rate of $83 \%$. However, they also found that the quality of the studies was generally low. In contrast to these findings in a randomized study, Bahr et. Al. [3] concluded that surgical treatment and eccentric strength training can produce significant improvement in terms of pain and function scores. It appears that about only $50 \%$ of all patients will be able to return to sport within one year after treatment with each option, and fewer still will have relief of all symptoms. In the absence of other validated treatment options, they suggested that eccentric training, a low-risk and lowcost option, should be tried before surgery is considered [3]. This information also suggests that operative procedures in athlete's tendons is not always effective. We believe that ASCs injection is justified before considering surgical treatment for patellar tendinopathy. Future studies are needed to (i) report on the cases where ASCs injections would result ineffective, and surgery would be needed and (ii) if ASCs injections would affect future surgical results.

Golman et.al [15]. showed that 91\% of PPTTs (Partial Patellar Tendon Tears) were found in the posterior and posteromedial portion of the tendon in patients with patellar tendinopathy. The most sensitive predictor for the

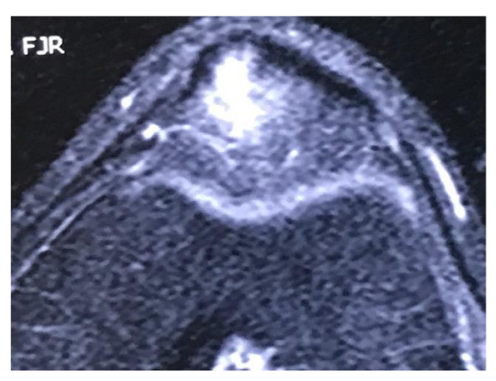

A
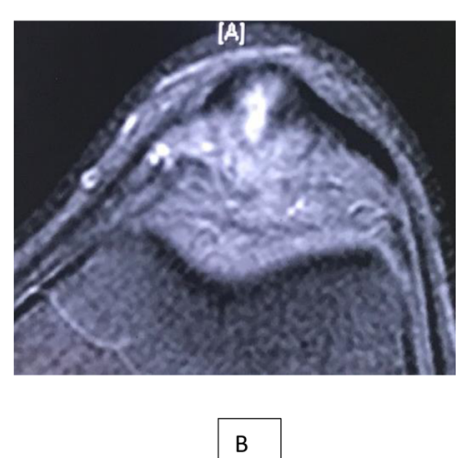

Fig. 6 A: Axial STIR MR image of the tear of the patellar tendon pre-injections or baseline. B: MRI axial view of the patellar tendon at 6 months post-injections 


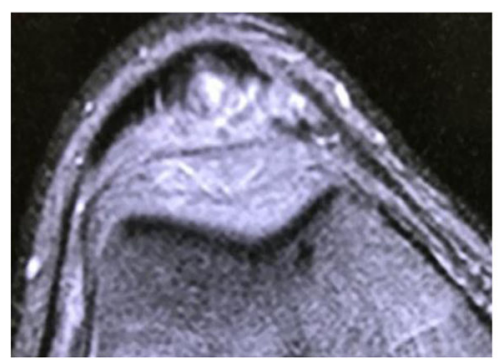

A

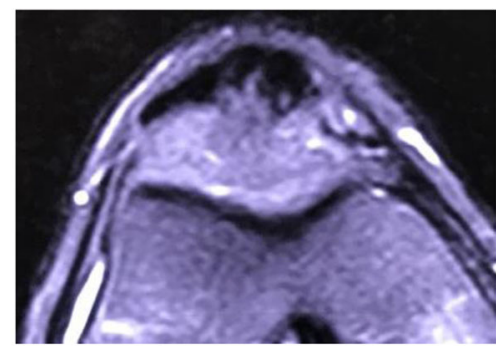

$\mathrm{B}$

Fig. 7 A Pre-injection axial STIR MR image showing injury of the patellar tendon and B: 6 months Post-injections axial view MRI showing partial healing of the tendon

presence of a partial tendon tear in their study was the thickness of the tendon, in which thickness $>8.8 \mathrm{~mm}$ was strongly correlated with the presence of a tear. In the present study patients' mean thickness was $12.8 \pm$ $1.1 \mathrm{~mm}$, and in agreement to the latter study we found in all the patients a tendon tear [15]. On MRI images we also found that there was an apparent delay between the observed clinical improvement and the structural repair as shown in the 6 months post-injection. MRI also allowed us to evaluate associated finding to insertional patellar tendinopathy. Ward et al. [39] hypothesized that fat pads contribute to the pathogenesis of tendinopathy by producing and delivering cytokines that drive the pathophysiology. The densely vascularized fat pad is the ideal origin for blood vessels infiltrating the tendon. These vessels deliver the cytokines produced in the fat pad to the tendon. In accordance with these findings, Ogon et al. [27] identified prognostic outcome factors in arthroscopic treatment of chronic PT. They found that preoperative infrapatellar fat pad edema (IFPE) alone or simultaneous bone marrow edema (BME) on preoperative MRI were associated with inferior functional outcome and delayed return to sports. Knowledge about these predictive factors might improve risk stratification, individualize treatment and postoperative rehabilitation, and contribute to improve clinical outcome. Moreover, current findings offer the potential for novel therapeutic approaches. In our study, no clear relationship between these associated MRI findings and outcome could be established. Patellar tendinopathy is frequently accompanied by changes in ultrasound and magnetic resonance imaging (MRI), such as tendon thickening, signal intensity changes and tears of the tendon, these changes could also occur in asymptomatic athletes [27]. The clear relationship between symptoms and pain in imaging studies is not well stablished [16].

Biological treatment of chronic patellar tendinopathy is challenging, mainly due to the low healing capacity of the tendons. This results in long and tedious therapies, therefore, identifying alternative strategies is a priority [1]. The tendon itself is relatively poor in cell number, with a low turnover rate [11]. The existing traditional view that focuses on the multipotent differentiation capacity of these cells should be expanded to include their equally interesting role as cellular modulators that brings them into a broader therapeutic scenario. These trophic

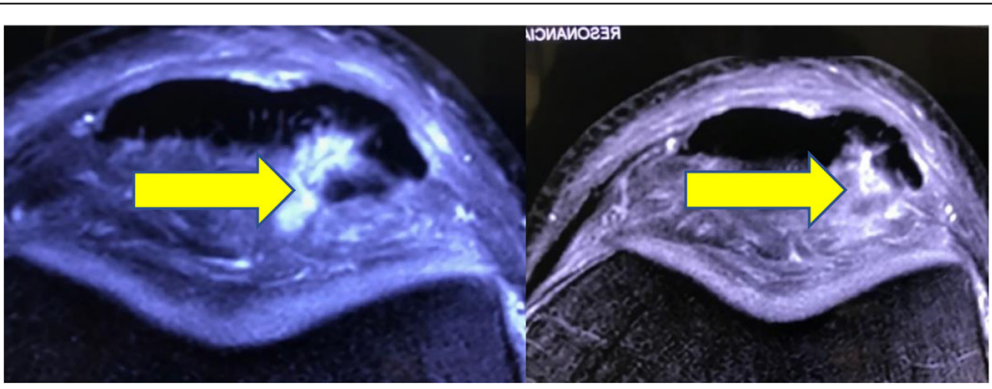

A

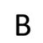

Fig. 8 A Pre-injection axial STIR MR image showing injury of the patellar tendon and B: 6 months Post-injections axial view MRI showing partial healing of the tendon. Observe Fat Pad Edema decreasing over a 6 months period. Yellow arrow 

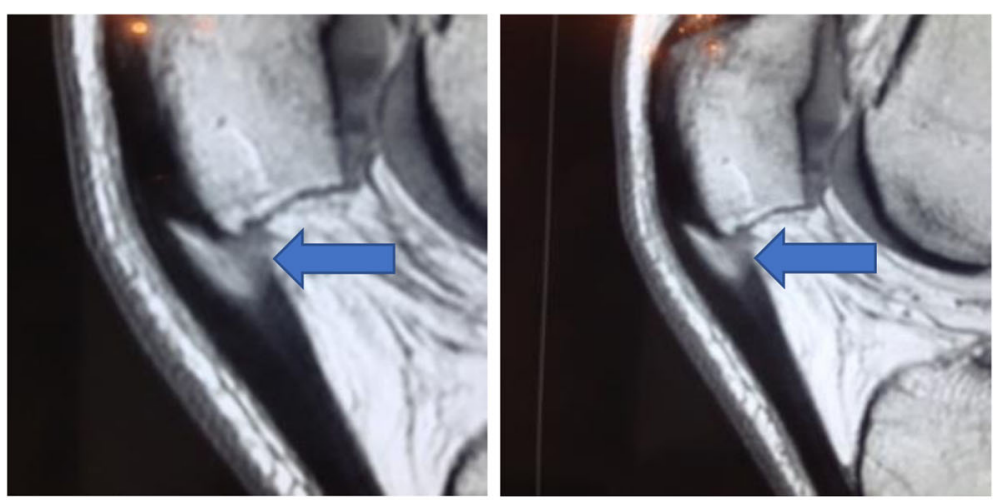

A

B
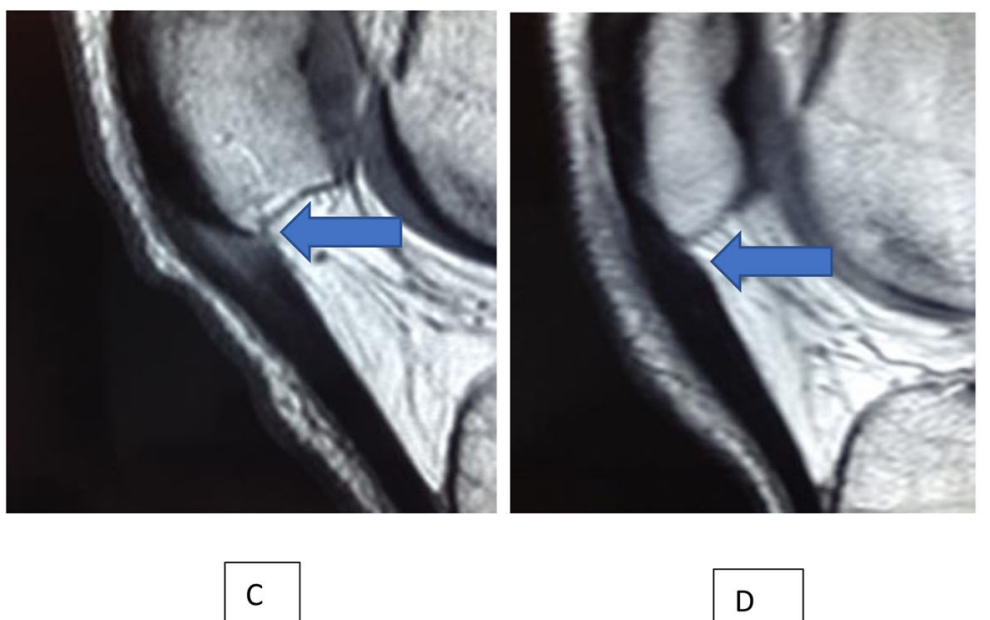

D

Fig. 9 Sagittal T1 MR images of insertional tendinopathy healing at (A) Baseline, (B), 3, (C), 6, and (D), 12 months post-injections. Note the decreasing area of tendinosis $\backslash$ Tear (Blue Arrows). Image D: Only a thickening of the tendon can be observed

and immunomodulatory activities suggest that MSCs may serve as site-regulated "drugstores" in vivo [7, 8]. The potential mechanisms of action proposed for MSCs are related to secretion of various cytokines and growth factors to adjacent cells, mainly recruiting macrophages and cells from the endothelial lineage. This is known as paracrine effect which may elicit cellular proliferation and damaged tissue healing [8]. A second mechanism would be through immunomodulatory properties that could improve healing of injured tissues, through inhibiting $\mathrm{T}$-cell proliferation and further affecting IL-2, IL10 signaling [33]. In spite of the little evidence for in vivo proliferation of delivered cells due to strong cellcell contact inhibition, lack of a ready mesenchymal cellfriendly niche and the lower atmospheric oxygen at the recipient tissue, a third potential mechanism could be related to the differentiation into targeted cell types and further contribution to wound repair [34].
The limitations of the present study are related to (i) the small number of knees involved (ii) the lack of a control group and (iii) the outcome assessors that were not blinded. One of the main concerns about safety of stromal cells is the potential for carcinogenesis. Previously reported experiences found no evidence of MSCs related tumor growth in more than 1000 patients treated for several conditions. Therefore, it looks like carcinogenic potential of MSCs might not be as high as previously thought [20]. Recently, the Food and Drug Administration (USA) warned of serious potential risks to patients from "stem cell therapies" administered for uses other than hematopoietic or immunologic reconstitution. Infections were also reported after reception of bacterially contaminated umbilical cord blood-derived stem cell products, intrathecal or intravitreally injections. In contrast to these reports, it is important to state that in cases of stem cell administration for tendon healing, 
adverse effects have not been reported until present [37]. In spite of this findings there is plenty of evidence based on the current clinical trials, that cultured MSCs therapy rather appears to be safe [23, 31]. In the present study there was only one patient with a mild hematoma and induration in the site of the obtention of the adipose tissue with spontaneous resolution In 4 days. Two patients withdrew consent at 3 and 6 months post-injections, and had surgery. We consider this as a ASCs treatment failure in this series. These patients presented among the largest BMI and Symptoms duration before intervention. This raises the question whether these variables would represent risk factors to intend a conservative treatment, which deserves appropriate research studies.

\section{Conclusion}

Despite the fact that two cases failed in this small series, treating chronic recalcitrant insertional PT by using expanded autologous ASCs injection in weight bearing sports' athletes demonstrated that the intervention was efficacious and safe in improving pain and performance until a 12-month follow-up period. Structural repair was also already significant at 6 months. In spite of the low level of evidence for use of stromal cells [29], this pilot study supports that 3 bi-weekly ASCs injections could be considered as a promising way to reverse the effects of degenerative process in chronic insertional PT. In the future well-designed, prospective randomized controlled trials are necessary to define the role of cell therapy in treating insertional PT.

\section{Abbreviations \\ ASCs: Adipose derived Stromal Cells; BM-MNCs: Bone marrow Mononuclear cells; BME: Bone marrow edema; ET: Eccentric Training; IFPE: Infrapatellar fat pad edema; MSCs: Mesenchymal Stromal Cells; MRI: Magnetic Resonance Imaging; MR: Magnetic Resonance; MCID: Minimal clinically Important difference; PRP: Platelet Rich Plasma; PT: Patellar Tendinopathy (insertional); PPTTS: Partial Patellar Tendon Tears; SVF: Stromal vascular fraction; VAS: Visual Analog Scale; Visa-P: Victorian Institute of sports assessment-patellar tendon questionnaire}

\section{Acknowledgements}

None.

\section{Authors' contributions}

Every author contributed and understand the whole manuscript data and conclusion. The authors read and approved the final manuscript.

\section{Funding}

None for the study

\section{Availability of data and materials \\ Available.}

\section{Declarations}

Ethics approval and consent to participate Available.

\section{Consent for publication}

Written in text

\section{Competing interests}

None.

\section{Author details}

${ }^{1}$ Cleveland Orthopedics, Buenos Aires, Argentina. ${ }^{2}$ Aspetar Qatar Orthopaedic and Sports Medicine Hospital, P.O. Box 29222, Doha, Qatar. ${ }^{3}$ Grupo Médico Rostagno, Buenos Aires, Argentina. ${ }^{4}$ Himan Centro de Diagnóstico por Imágenes, Buenos Aires, Argentina.

Received: 27 May 2021 Accepted: 2 June 2021

Published online: 02 July 2021

\section{References}

1. Abat F, Alfredson H, Cucchiarini M, Madry H, Marmotti A, Mouton C et al (2017) Current trends in tendinopathy: consensus of the ESSKA basic science committee. Part I: biology, biomechanics, anatomy and an exercisebased approach. J Exp Orthop 4(1):18

2. Baer PC, Geiger H (2012) Adipose-derived mesenchymal stromal/stem cells: tissue localization, characterization, and heterogeneity. Stem Cells Int:812693

3. Bahr R, Fossan B, Løken S, Engebretsen L (2006) Surgical treatment compared with eccentric training for patellar tendinopathy (Jumper's knee). A randomized, controlled trial. J Bone Joint Surg Am 88(8):1689-1698

4. Bi Y, Ehirchiou D, Kilts TM, Inkson CA, Embree MC, Sonoyama W, Li L, Leet Al, Seo BM, Zhang L, Shi S, Young MF (2007) Identification of tendon stem/ progenitor cells and the role of the extracellular matrix in their niche. Nat Med 13(10):1219-1227. https://doi.org/10.1038/nm1630

5. Blazina ME, Kerlan RK, Jobe FW, Carter VS, Carlson GJ (1973) Jumper's knee. Orthop Clin North Am 4(3):665-678

6. Briggs KK, Steadman JR, Hay CJ, Hines SL (2009) Lysholm score and Tegner activity level in individuals with Normal knees. Am J Sports Med 37(5):898901. https://doi.org/10.1177/0363546508330149

7. Caplan Al, Correa D (2011) The MSC: an injury drugstore. Cell Stem Cell 9(1): 11-15. https://doi.org/10.1016/j.stem.2011.06.008

8. Chen L, Tredget EE, Wu PYG, Wu Y (2008) Paracrine factors of mesenchymal stem cells recruit macrophages and endothelial lineage cells and enhance wound healing. PloS One 3(4):e1886

9. Clarke AW, Alyas F, Morris T, Robertson CJ, Bell J, Connell DA (2011) Skinderived tenocyte-like cells for the treatment of patellar tendinopathy. Am J Sports Med 39(3):614-623. https://doi.org/10.1177/0363546510387095

10. Coleman BD, Khan KM, Maffulli N, Cook JL, Wark JD (2000) Studies of surgical outcome after patellar tendinopathy: clinical significance of methodological deficiencies and guidelines for future studies. Victorian Institute of Sport Tendon Study Group. Scand J Med Sci Sports 10(1):2-11. https://doi.org/10.1034/j.1600-0838.2000.010001002.x

11. Costa-Almeida R, Calejo I, Gomes ME (2019) Mesenchymal stem cells empowering tendon regenerative therapies. Int J Mol Sci 20(12). https://doi. org/10.3390/ijms20123002

12. Crossley KM, Bennell KL, Cowan SM, Green S (2004) Analysis of outcome measures for persons with patellofemoral pain: which are reliable and valid? Arch Phys Med Rehabil 85(5):815-822. https://doi.org/10.1016/S0003-9993(03)00613-0

13. Dan M, Parr W, Broe D, Cross M, Walsh WR (2018) Biomechanics of the knee extensor mechanism and its relationship to patella tendinopathy: a review. J Orthop Res 36(12):3105-3112. https://doi.org/10.1002/jor.24120

14. Dominici M, Le Blanc K, Mueller I, Slaper-Cortenbach I, Marini F, Krause D et al (2006) Minimal criteria for defining multipotent mesenchymal stromal cells. The International Society for Cellular Therapy position statement. Cytotherapy. 8(4):315-317. https://doi.org/10.1080/14653240600855905

15. Golman M, Wright ML, Wong TT, Lynch TS, Ahmad CS, Thomopoulos S, Popkin CA (2020) Rethinking patellar tendinopathy and partial patellar tendon tears: a novel classification system. Am J Sports Med 48(2):359-369. https://doi.org/10.1177/0363546519894333

16. Hernandez-Sanchez S, Hidalgo MD, Gomez A (2014) Responsiveness of the VISA-P scale for patellar tendinopathy in athletes. Br I Sports Med 48(6):453457. https://doi.org/10.1136/bjsports-2012-091163

17. Hoksrud A, Öhberg L, Alfredson H, Bahr R (2006) Ultrasound-guided sclerosis of Neovessels in painful chronic patellar tendinopathy: a randomized controlled trial. Am J Sports Med 34(11):1738-1746. https://doi. org/10.1177/0363546506289168

18. Kettunen JA, Kvist M, Alanen E, Kujala UM (2002) Long-term prognosis for jumper's knee in male athletes. A prospective follow-up study. Am J Sports Med 30(5):689-692. https://doi.org/10.1177/03635465020300051001 
19. Khoury M, Tabben M, Rolón AU, Levi L, Chamari K, D’Hooghe P (2021) Promising improvement of chronic lateral elbow tendinopathy by using adipose derived mesenchymal stromal cells: a pilot study. J Exp Orthop 8(1): 6. https://doi.org/10.1186/s40634-020-00320-z

20. Klopp AH, Gupta A, Spaeth E, Andreeff M, Marini F 3rd. (2011) Concise review: dissecting a discrepancy in the literature: do mesenchymal stem cells support or suppress tumor growth? Stem Cells 29(1):11-19. https://doi. org/10.1002/stem.559

21. Kongsgaard M, Kovanen V, Aagaard P, Doessing S, Hansen P, Laursen AH, Kaldau NC, Kjaer M, Magnusson SP (2009) Corticosteroid injections, eccentric decline squat training and heavy slow resistance training in patellar tendinopathy. Scand J Med Sci Sports 19(6):790-802. https://doi. org/10.1111/j.1600-0838.2009.00949.x

22. Korakakis V, Whiteley R, Tzavara A, Malliaropoulos N (2018) The effectiveness of extracorporeal shockwave therapy in common lower limb conditions: a systematic review including quantification of patient-rated pain reduction. Br J Sports Med 52(6):387-407. https://doi.org/10.1136/bjsports-2016-097347

23. Lalu MM, McIntyre L, Pugliese C, Fergusson D, Winston BW, Marshall JC, Granton J, Stewart DJ, Canadian Critical Care Trials Group (2012) Safety of cell therapy with mesenchymal stromal cells (SafeCell): a systematic review and meta-analysis of clinical trials. PLoS One 7(10):e47559. https://doi.org/1 0.1371/journal.pone.0047559

24. Lian $\varnothing$, Scott A, Engebretsen L, Bahr R, Duronio V, Khan K (2007) Excessive apoptosis in patellar tendinopathy in athletes. Am J Sports Med 35(4):605611. https://doi.org/10.1177/0363546506295702

25. Lian OB, Engebretsen L, Bahr R (2005) Prevalence of jumper's knee among elite athletes from different sports: a cross-sectional study. Am J Sports Med 33(4):561-567. https://doi.org/10.1177/0363546504270454

26. Müller SA, Todorov A, Heisterbach PE, Martin I, Majewski M (2015) Tendon healing: an overview of physiology, biology, and pathology of tendon healing and systematic review of state of the art in tendon bioengineering. Knee Surg Sports Traumatol Arthrosc 23(7):2097-2105. https://doi.org/10.1 007/s00167-013-2680-z

27. Ogon P, Izadpanah K, Eberbach H, Lang G, Südkamp NP, Maier D (2017) Prognostic value of MRI in arthroscopic treatment of chronic patellar tendinopathy: a prospective cohort study. BMC Musculoskelet Disord 18(1): 146

28. Orbay H, Tobita M, Mizuno H (2012) Mesenchymal stem cells isolated from adipose and other tissues: basic biological properties and clinical applications. Stem Cells Int:461718

29. Pas H, Moen MH, Haisma HJ, Winters M (2017) No evidence for the use of stem cell therapy for tendon disorders: a systematic review. Br J Sports Med 51(13):996-1002. https://doi.org/10.1136/bjsports-2016-096794

30. Pascual-Garrido C, Rolón A, Makino A (2012) Treatment of chronic patellar tendinopathy with autologous bone marrow stem cells: a 5-year-followup. Stem Cells Int:953510

31. Peeters CM, Leijs MJ, Reijman M, van Osch GJ, Bos PK (2013) Safety of intraarticular cell-therapy with culture-expanded stem cells in humans: a systematic literature review. Osteoarthr Cartil 21(10):1465-1473. https://doi. org/10.1016/j.joca.2013.06.025

32. Purdam CR, Jonsson P, Alfredson H, Lorentzon R, Cook JL, Khan KM (2004) A pilot study of the eccentric decline squat in the management of painful chronic patellar tendinopathy. Br J Sports Med 38(4):395-397. https://doi. org/10.1136/bjsm.2003.000053

33. Rasmusson I, Ringdén O, Sundberg B, Le Blanc K (2005) Mesenchymal stem cells inhibit lymphocyte proliferation by mitogens and alloantigens by different mechanisms. Exp Cell Res 305(1):33-41. https://doi.org/10.1016/j. yexcr.2004.12.013

34. Sasaki M, Abe R, Fujita Y, Ando S, Inokuma D, Shimizu H (2008) Mesenchymal stem cells are recruited into wounded skin and contribute to wound repair by transdifferentiation into multiple skin cell type. J Immunol 180(4):2581-2587. https://doi.org/10.4049/jimmunol.180.4.2581

35. Scott A, LaPrade RF, Harmon KG, Filardo G, Kon E, Della Villa S et al (2019) Platelet-rich plasma for patellar tendinopathy: a randomized controlled trial of leukocyte-rich PRP or leukocyte-poor PRP versus saline. Am J Sports Med 47(7):1654-1661. https://doi.org/10.1177/0363546519837954

36. Sugaya H, Yoshioka T, Kato T, Taniguchi Y, Kumagai H, Hyodo K et al (2018) Comparative analysis of cellular and growth factor composition in bone marrow aspirate concentrate and platelet-rich plasma. Bone Marrow Res: 1549826
37. van den Boom NAC, Winters M, Haisma HJ, Moen MH (2020) Efficacy of stem cell therapy for tendon disorders: a systematic review. Orthop J Sports Med 8(4):2325967120915857

38. Visentini PJ, Khan KM, Cook JL, Kiss ZS, Harcourt PR, Wark JD (1998) The VISA score: an index of severity of symptoms in patients with jumper's knee (patellar tendinosis). Victorian Institute of Sport Tendon Study Group. J Sci Med Sport 1(1):22-28. https://doi.org/10.1016/S1440-2440(98)80005-4

39. Ward E, Andersson G, Backman L, Gaida J (2016) Fat pads adjacent to tendinopathy: more than a coincidence? Br J Sports Med:50

\section{Publisher's Note}

Springer Nature remains neutral with regard to jurisdictional claims in published maps and institutional affiliations.

\section{Submit your manuscript to a SpringerOpen ${ }^{\circ}$ journal and benefit from:}

- Convenient online submission

- Rigorous peer review

- Open access: articles freely available online

High visibility within the field

- Retaining the copyright to your article

Submit your next manuscript at $\boldsymbol{\nabla}$ springeropen.com 